\title{
Impact of hospitalizations for bronchiolitis in preterm infants on long-term health care costs in Italy: a retrospective case-control study
}

This article was published in the following Dove Press journal:

ClinicoEconomics and Outcomes Research

4 August 2016

Number of times this article has been viewed

\author{
Daniela Paola Roggeri' \\ Alessandro Roggeri' \\ Elisa Rossi ${ }^{2}$ \\ Salvatore Cataudella ${ }^{2}$ \\ Nello Martini ${ }^{3}$ \\ 'ProCure Solutions, Nembro, \\ Bergamo, ${ }^{2} \mathrm{CINECA}$ Interuniversity \\ Consortium, Bologna, ${ }^{3}$ Accademia \\ Nazionale di Medicina, Rome, Italy
}

Correspondence: Alessandro Roggeri ProCure Solutions, Via Camozzi I/C, Nembro, Bergamo 24027, Italy Tel +39035 52। 121

Email alessandro.roggeri@ procuresolutions.it
Purpose: Bronchiolitis is an acute inflammatory injury of the bronchioles, and is the most frequent cause of hospitalization for lower respiratory tract infections in preterm infants. This was a retrospective, observational, case-control study conducted in Italy, based on administrative database analysis. The aim of this study was to evaluate differences in health care costs of preterm infants with and without early hospitalization for bronchiolitis.

Patients and methods: Preterm infants born in the period between January 1, 2009 and December 31, 2010 and hospitalized for bronchiolitis in the first year of life were selected from the ARNO Observatory database and observed for the first 4 years of life. These preterm infants were compared (paired 1-3) with preterm infants who were not hospitalized for bronchiolitis in the first year of life and with similar characteristics. Only direct health care costs reimbursed by the Italian National Health Service were considered for this study (drugs, hospitalizations, and diagnostic/therapeutic procedures).

Results: Of 40,823 newborns in the accrual period, 863 were preterm with no evidence of prophylaxis, and 22 preterm infants were hospitalized for bronchiolitis (cases) and paired with 62 controls. Overall, cases had $74 \%$ higher average cost per infant in the first 4 years of life than controls $(18,624 €$ versus $10,189 €$, respectively). The major cost drivers were hospitalizations, accounting for $>90 \%$ in both the populations. The increase in total yearly health care cost between cases and controls remained substantial even in the fourth year of life for all cost items. A relevant increase in hospitalizations and drug consumption linked to respiratory tract diseases was noted in infants hospitalized for bronchiolitis during the entire follow-up period. Conclusion: Preterm infants hospitalized for bronchiolitis in the first year of life were associated with increased resource consumption and costs throughout the entire period of observation; even in the fourth year, the difference versus paired controls was relevant.

Keywords: bronchiolitis, cost, preterm, hospitalizations

\section{Introduction}

Bronchiolitis is an acute respiratory illness that affects young children and infants, causing obstruction in the small airways (bronchioles) of the lung, and represents the most frequent cause of hospitalization due to lower respiratory tract infection (LRTI) in preterm infants in the US. ${ }^{1-4}$ A hospitalization due to bronchiolitis occurs in $\sim 3 \%$ of all infants younger than 1 year in the US and Europe ${ }^{5}$ and hospitalizations usually occur during the epidemic season; in Italy, a recent study ${ }^{6}$ found a 5.4\% rate of hospitalization for bronchiolitis in preterm infants in the first 12 months of life.

Bronchiolitis is a distressing, potentially life-threatening respiratory condition that affects young babies. Its initial symptoms could be similar to those of a common cold, 
but in a few days, they can progress to cough, wheezing, and difficulty in breathing. The vast majority of affected children get better with home care, but a very small percentage of them require hospitalization. ${ }^{5,7}$ The most frequent cause of bronchiolitis is a viral infection, mainly represented by respiratory syncytial virus (RSV) which is responsible for $\sim 70 \%$ of bronchiolitis during the epidemic season. ${ }^{8}$ During childhood, infants with an early episode of severe LRTIs (like bronchiolitis requiring hospitalization) are frequently affected by wheezing, asthma, and allergy. ${ }^{9,10}$ These conditions characterize this population even in adulthood, as reported by a study conducted by Sigurs et al $^{11}$ in a cohort of 47 subjects with hospitalization for an RSV infection in the first year of life compared with 92 controls followed until 18 years of age; this study reveals a higher frequency of asthma, allergy, and allergic sensitization persisting in early adulthood in the RSV cohort. Hospitalizations for RSV bronchiolitis were the only significant risk factor for the presence of these pathologies in these young adults. Similar findings were reported by Backman et $\mathrm{al}^{12}$ regarding the increased risk of asthma and use of asthma medication in adults aged 28-31 years who suffered from bronchiolitis or an LRTI caused by RSV with wheezing in early childhood.

The aim of the present study was to evaluate resource consumption and costs reimbursed by the Italian National Health Service (INHS) (drugs, hospitalizations, diagnostic and therapeutic procedures) in the first 4 years of life for the management of preterm infants without prophylaxis for RSV with at least one hospitalization for bronchiolitis in the first year of life; these costs were compared with those associated with the treatment of a cohort of preterm infants with similar characteristics without any hospitalization for bronchiolitis in the first year of life.

\section{Materials and methods}

The present study is a retrospective, observational, noninterventional, case-control study performed from the perspective of the INHS based on the administrative databases from ARNO Observatory (provided by CINECA Interuniversity Consortium). ${ }^{13}$ Population-based, health care-related data (from several local health units across Italy) are reported in the ARNO Observatory, an online, multicenter, observational database. For each subject, the data are combined and aggregated through epidemiological methods. Data reported in the ARNO Observatory database include demographic characteristics, drug consumption, hospitalizations, and diagnostic and therapeutic procedures. In the present study, we analyzed data starting from a population of $\sim 2.4$ million inhabitants from five local health units, of whom 40,823 were newborns in 2009 and
2010 (58.8\% came from northern regions, $28.8 \%$ from central regions, and $12.3 \%$ from southern regions of the country). For the purpose of the present study, all preterm infants (gestational age $\leq 36$ weeks) born in the period between January 1, 2009 and December 31, 2010 and hospitalized at least once due to bronchiolitis in the first year of life were selected and observed for the first 4 years of life. In the same selection period, this population (cases) was paired with three preterm infants (controls, extracted from the preterm infant population) who were not hospitalized for bronchiolitis in the first year of life and of the same sex, gestational age, and season of birth.

Prematurity status at birth was defined through International Classification of Diseases, Ninth Revision, Clinical Modification (ICD9-CM) ${ }^{14}$ codes 765.21-765.28 (<24 completed weeks of gestation to 35-36 completed weeks of gestation).

Hospitalizations for bronchiolitis were identified through the following ICD9-CM codes: 466.1 (acute bronchiolitis), 466.11 (acute bronchiolitis due to RSV), and/or 466.19 (acute bronchiolitis due to other infectious organisms).

Newborns with known RSV prophylaxis with palivizumab in the first year of life were excluded from the present analysis.

As the present study assumed the perspective of the INHS, the following health care resources were evaluated: drugs reimbursed by the INHS (prices reimbursed by INHS), diagnostic and therapeutic procedures (Italian national tariffs), and hospital admissions (Italian national tariffs for the provision of hospital care).

\section{Statistical analysis}

Direct health care costs of the two cohorts were described by mean and standard deviation. Differences between cases and controls in costs per infant per year were assessed by Wilcoxon-Mann-Whitney nonparametric tests. Two-sided $P$-values $<0.05$ were considered statistically significant.

\section{Ethics}

As the study was retrospective, observational, noninterventional, and data were extracted from the administrative database of Arno Observatory in an anonymous way, the ethical committee's evaluation was not necessary.

\section{Results}

Out of a total analyzed population of 2,400,227 subjects, there were 40,823 newborns in the accrual period; among them, 863 were preterm infants not treated with RSV prophylaxis, and 22 (41\% females) were hospitalized for bronchiolitis in the first year of life. Sixty-two paired controls with similar 


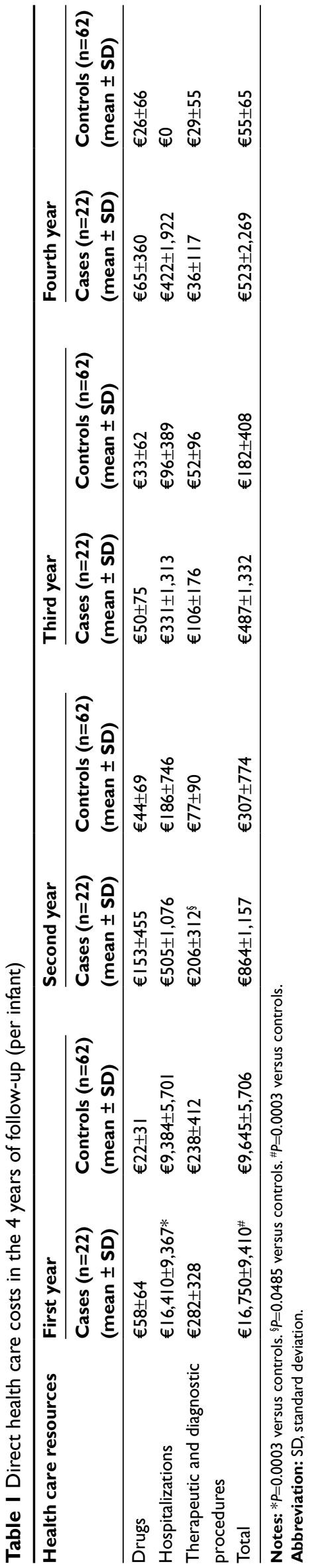

characteristics and who were not hospitalized for bronchiolitis were identified. Among infants hospitalized for bronchiolitis, $9.1 \%$ had bronchopulmonary dysplasia, and $4.5 \%$ had cardiovascular pathologies.

On average, preterm infants hospitalized for bronchiolitis (cases) had $83 \%$ higher average cost per infant over 4 years than those not hospitalized for bronchiolitis (controls) $(18,624 €$ versus $10,189 €$, respectively). As a whole, during the 4 years of follow-up, the major cost driver was hospitalizations, accounting for $>90 \%$ in both the populations.

Detailed costs per year of life are reported in Table 1.

Cases were associated with higher total costs compared to controls in each year of life in all the considered cost components. Health care costs related to the treatment of cases remained substantially higher than those of controls even in the fourth year of life ( $523 € /$ infant versus $55 € /$ infant, respectively), although data referring to year three and four should be interpreted considering the limited sample size; the most important drivers of this difference were hospital admissions and drug consumption.

The increased expenditure associated with infants hospitalized for bronchiolitis was consistent over all the weeks of gestational ages and over the entire follow-up of 4 years as detailed in Table 2.

Considering hospitalizations for major diagnostic category 04 (diseases and disorders of the respiratory system), as detailed in Table 3, cases were associated with substantially higher costs ( $4,455 € /$ infant versus $138 € /$ infant over 4 years, respectively) and percentage of admitted infants versus controls; moreover, although among the controls only $1.6 \%$ of patients were hospitalized with a diagnosis belonging to major diagnostic category 04 after the first year of life, among cases, in the same period, $18.2 \%$ of infants were hospitalized with this diagnosis.

Over the 4 years of observation, infants hospitalized for bronchiolitis were associated with higher costs for the use of drugs for obstructive airway diseases $(+258 \%)$, systemic antibiotics $(+33 \%)$, and systemic corticosteroids ( $+247 \%)$. Major anatomical therapeutic chemical drug classes in terms of per capita expenditure are reported in Table 4.

Table 2 Direct health care costs in the 4 years of follow-up by gestational age (per infant)

\begin{tabular}{lll}
\hline wGA & \multicolumn{2}{l}{ Four years of follow-up costs per infant } \\
\cline { 2 - 3 } & Cases $(\mathbf{n}=22)$ (mean & Controls $(\mathbf{n}=62)$ (mean \\
& \pm SD) & \pm SD) \\
\hline$\leq 28$ & $€ 23,689 \pm 9,757$ & $€ I 6,194 \pm 5,434$ \\
$29-30$ & $€ 19,340 \pm 3,973$ & $€ I 7,088 \pm 4, \mid 49$ \\
$31-34$ & $€ I 5,430 \pm 6,038$ & $€ 8,708 \pm 4,813$ \\
$35-36$ & $€|8,073 \pm| 7,567$ & $€ 7,009 \pm 3,739$ \\
\hline
\end{tabular}

Abbreviations: wGA, weeks of gestational age; SD, standard deviation. 
Table 3 Costs per infant for hospitalizations due to diseases and disorders of the respiratory system in the 4 years of follow-up

\begin{tabular}{|c|c|c|c|c|}
\hline \multirow[t]{2}{*}{ Populations } & \multicolumn{2}{|l|}{ First year of follow-up } & \multicolumn{2}{|l|}{ Second to fourth year of follow-up } \\
\hline & $\begin{array}{l}\text { Hospitalization cost per infant } \\
(\text { MDC04) (mean } \pm \text { SD) }\end{array}$ & $\begin{array}{l}\text { Percentage of hospitalized } \\
\text { infants }\end{array}$ & $\begin{array}{l}\text { Hospitalization cost per infant } \\
\text { (MDC04) (mean } \pm \text { SD) }\end{array}$ & $\begin{array}{l}\text { Percentage of } \\
\text { hospitalized infants }\end{array}$ \\
\hline Cases $(n=22)$ & $€ 3,703 \pm 12,875$ & 86.4 & $€ 752 \pm 4,598$ & 18.2 \\
\hline Controls $(n=62)$ & $€ 8 I \pm 8,924$ & 3.2 & $€ 57 \pm 2,521$ & 1.6 \\
\hline
\end{tabular}

Abbreviations: MDC, major diagnostic category; SD, standard deviation.

Table 4 Drug expenditure per infant in the 4 years of follow-up

\begin{tabular}{|c|c|c|c|c|c|c|c|c|c|}
\hline \multirow{2}{*}{$\begin{array}{l}\text { ATC } \\
\text { classes }\end{array}$} & \multirow[t]{2}{*}{ ATC description } & \multicolumn{2}{|c|}{ First year } & \multicolumn{2}{|c|}{ Second year } & \multicolumn{2}{|c|}{ Third year } & \multicolumn{2}{|c|}{ Fourth year } \\
\hline & & $\begin{array}{l}\text { Cases } \\
(n=22)\end{array}$ & $\begin{array}{l}\text { Controls } \\
(n=62)\end{array}$ & $\begin{array}{l}\text { Cases } \\
(n=22)\end{array}$ & $\begin{array}{l}\text { Controls } \\
(n=62)\end{array}$ & $\begin{array}{l}\text { Cases } \\
(n=22)\end{array}$ & $\begin{array}{l}\text { Controls } \\
(n=62)\end{array}$ & $\begin{array}{l}\text { Cases } \\
(n=22)\end{array}$ & $\begin{array}{l}\text { Controls } \\
(n=62)\end{array}$ \\
\hline R03 & $\begin{array}{l}\text { Drugs for obstructive } \\
\text { airway diseases }\end{array}$ & $€ 31.5$ & $€ 7.0$ & $€ 53.3$ & $€ 23.1$ & $€ 26.7$ & $€ 19.4$ & $€ 41.7$ & $€ 9.8$ \\
\hline J0I & $\begin{array}{l}\text { Antibacterials for systemic } \\
\text { use }\end{array}$ & $€ I I .8$ & $€ 8.4$ & $€ \mid 4.4$ & $€ 16.5$ & $€ 20.6$ & $€ 12.0$ & $€ 21.2$ & $€ \mid 4.4$ \\
\hline $\mathrm{A} 02$ & $\begin{array}{l}\text { Drugs for acid-related } \\
\text { disorders }\end{array}$ & $€ 6.1$ & $€ 1.9$ & $€ 1.6$ & $€ 1.2$ & $€ 0$ & $€ 0.2$ & $€ 0$ & $€ 0$ \\
\hline B03 & Antianemic preparations & $€ 3.9$ & $€ 2.3$ & $€ 0$ & $€ 0.5$ & $€ 0$ & $€ 0.3$ & $€ 0$ & $€ 0.2$ \\
\hline All & Vitamins & $€ 2.3$ & $€ 1.8$ & $€ 0$ & $€ 0.9$ & $€ 0$ & $€ 0.3$ & $€ 0.3$ & $€ 0.3$ \\
\hline $\mathrm{H} 02$ & $\begin{array}{l}\text { Corticosteroids for } \\
\text { systemic use }\end{array}$ & $€ 1.6$ & $€ 0.6$ & $€ 0.8$ & $€ 0.6$ & $€ \mid .4$ & $€ 0.4$ & $€ 0.9$ & $€ 0.3$ \\
\hline
\end{tabular}

Abbreviation: ATC, anatomical therapeutic chemical classification system.

Among diagnostic and therapeutic procedures, outpatient visits were the major cost driver; in the first 4 years of life, cases were associated with an average expenditure for outpatient visits of $311 € /$ infant versus $202 € /$ infant of controls $(+54 \%)$.

\section{Discussion}

This study highlights that preterm infants hospitalized for bronchiolitis in the first year of life are associated with substantially higher health care resource consumption and related costs than preterm infants not hospitalized for bronchiolitis in the first year of life; these differences are maintained at least over a period of 4 years.

A few studies on the costs and resource consumption of patients with severe bronchiolitis, particularly focused only on the costs of bronchiolitis hospitalization ${ }^{15-17}$ or with short observational period, ${ }^{18-20}$ are currently available at an international level; for this reason, due to differences in the types of cost items considered, study structure/period of observation, and health care reimbursement setting, a comparison with this analysis could not be deemed suitable.

In recent years, administrative database analyses are considered valuable tools to observe the real-world practice and some relevant clinical/economic consequences in large populations observed for long periods of time, particularly regarding low-incidence clinical events and outcomes. Administrative data sets could be considered an interesting source of "real-world" health care data on a large population of unselected patients..$^{21}$ Moreover, as data reported in the administrative databases are reliable and associated with standardized coding systems (ie, ICD9$\mathrm{CM}$ ), they can be used for health care utilization purposes and cost estimation. ${ }^{22}$

A major limitation to the use of administrative databases is that they were created for health care policy purposes ${ }^{22-24}$ and could therefore be lacking information that could be valuable for research purposes.

A major limitation of this study is that, as hospitalizations for bronchiolitis are not so frequent, even in preterm infants, the observed population, as expected, is small, although the reference population from which the preterm infants were extracted is wide $(>2,400,000$ subjects, over 40,000 newborns). In the evaluation of the selection criteria/timing, it should be considered that, in Italy, ICD9-CM 2007 version, ${ }^{25}$ which allows the identification of the specific gestational ages, was adopted in the year 2009; for this reason, it was not possible to enlarge the selection period (and consequently the observed populations) maintaining the observational period of 4 years.

It should also be considered that, as data were extracted from administrative databases, there were no specific data regarding the severity of the pathology and on comorbidities, which can allow an estimate of the detailed clinical characteristics of the patients. 
The most important strengths of this analysis are linked to the administrative database structure in which data for each patient were systematically collected and recorded, given the possibility to longitudinally observe a specific cohort of subjects for long periods of time. In our case, as far as we know, this is the first Italian study with real-world evidence on bronchiolitis-related costs with a relatively long observational period. Moreover, the presence of a control group of preterm infants with similar characteristics as that of the cases and without bronchiolitis allows the estimation of the differences in resource consumption between the two populations.

This study, despite having several limitations linked to the data source and limited sample size, highlights the economic relevance of early hospitalization for bronchiolitis in preterm infants. The wide increase in the economic cost of these populations compared with preterm infants without severe bronchiolitis is maintained over the entire observational period of 4 years, supporting the possibility that babies with an acute and severe case of bronchiolitis in the first year of life could have long-lasting clinical consequences, ${ }^{11,12}$ as also highlighted in literature, and pose a related important economic burden on health care services.

\section{Acknowledgments}

The authors would like to thank Silvia Calabria, Letizia Dondi, Antonella Pedrini (CORE Collaborative Outcome Research, Bologna, Italy), and Marisa De Rosa (CINECA Interuniversity Consortium, Casalecchio di Reno, Bologna, Italy) for revising the analysis plan and helping in the interpretation of results.

\section{Author contributions}

DPR, AR, and ER conceived the study, and prepared the protocol and the analysis plan. ER and SC performed the analysis. DPR, AR, ER, and NM critically revised the data. DPR, AR, and ER wrote the manuscript. All authors contributed toward data analysis, drafting and critically revising the paper, gave final approval of the version to be published, and agree to be accountable for all aspects of the work.

\section{Disclosure}

The authors declare that they have no conflict of interest regarding this work.

\section{References}

1. Boyce TG, Mellen BG, Mitchel EF Jr, Wright PF, Griffin MR. Rates of hospitalization for respiratory syncytial virus infection among children in medicaid. J Pediatr. 2000;137(6):865-870.
2. Leader S, Kohlhase K. Recent trends in severe respiratory syncytial virus (RSV) among US infants; 1997 to 2000. J Pediatr. 2003;143(5 Suppl): S127-S132.

3. Nair H, Nokes DJ, Gessner BD, et al. Global burden of acute lower respiratory infections due to respiratory syncytial virus in young children: a systematic review and meta-analysis. Lancet. 2010;375(9725):1545-1555.

4. Hall CB, Weinberg GA, Iwane MK, et al. The burden of respiratory syncytial virus infection in young children. NEngl JMed. 2009;360(6):588-598.

5. Smyth RL, Openshaw PJ. Bronchiolitis. Lancet. 2006;368:312-322.

6. Lanari M, Prinelli F, Adorni F, et al. Risk factors for bronchiolitis hospitalization during the first year of life in a multicenter Italian birth cohort. Ital J Pediatr. 2015;41:40.

7. Lozano JM. Bronchiolitis. Clin Evid. 2004;(12):370-384.

8. Henrickson KJ, Hoover S, Kehl KS, Hua W. National disease burden of respiratory viruses detected in children by polymerase chain reaction. Pediatr Infect Dis J. 2004;23(1 Suppl):S11-S18.

9. Gelfand EW. Pediatric asthma: a different disease. Proc Am Thorac Soc. 2009;6(3):278-282.

10. Walton RP, Johnston SL. Role of respiratory viral infections in the development of atopic conditions. Curr Opin Allergy Clin Immunol. 2008;8(2): $150-153$.

11. Sigurs N, Aljassim F, Kjellman B, et al. Asthma and allergy patterns over 18 years after severe RSV bronchiolitis in the first year of life. Thorax. 2010;65(12):1045-1052.

12. Backman K, Piippo-Savolainen E, Ollikainen H, Koskela H, Korppi M. Increased asthma risk and impaired quality of life after bronchiolitis or pneumonia in infancy. Pediatr Pulmonol. 2014;49(4):318-325.

13. ARNO Osservatorio [database on the Internet]. CINECA. Available from: http://osservatorioarno.cineca.org. Accessed February 16, 2016.

14. World Health Organization. International Classification of Diseases (ICD): 9th Revision, Basic Tabulation List with Alphabetic Index. Geneva: World Health Organization; 1978.

15. Heikkilä P, Forma L, Korppi M. Hospitalisation costs for infant bronchiolitis are up to 20 times higher if intensive care is needed. Acta Paediatr. 2015;104(3):269-273.

16. Gil-Prieto R, Gonzalez-Escalada A, Marín-García P, et al. Respiratory syncytial virus bronchiolitis in children up to 5 years of age in Spain: epidemiology and comorbidities: an observational study. Medicine (Baltimore). 2015;94(21):e831.

17. Pelletier AJ, Mansbach JM, Camargo CA Jr. Direct medical costs of bronchiolitis hospitalizations in the United States. Pediatrics. 2006;118(6): 2418-2423.

18. Palmer L, Hall CB, Katkin JP, et al. Respiratory outcomes, utilization and costs 12 months following a respiratory syncytial virus diagnosis among commercially insured late-preterminfants. Curr MedRes Opin. 2011;27(2): 403-412.

19. Palmer L, Hall CB, Katkin JP, et al. Healthcare costs within a year of respiratory syncytial virus among Medicaid infants. Pediatr Pulmonol. 2010;45(8):772-781.

20. Creery D, Lyer P, Samson L, Coyle D, Osborne G, MacDonald A. Costs associated with infant bronchiolitis in the Baffin region of Nunavut. Int J Circumpolar Health. 2005;64(1):38-45.

21. Sarrazin MS, Rosenthal GE. Finding pure and simple truths with administrative data. JAMA. 2012;307(13):1433-1435.

22. Part I. Introduction to Performance Data (continued). Updated October 2014. Agency for Healthcare Research and Quality, Rockville, MD. Available at: http://www.ahrq.gov/professionals/quality-patient-safety/ quality-resources/tools/perfmeasguide/perfmeaspt1a.html. Accessed February 16, 2016.

23. Hertzer NR. Reasons why data from the Nationwide Inpatient Sample can be misleading for carotid endarterectomy and carotid stenting. Semin Vasc Surg. 2012;25(1):13-17.

24. Haut ER, Pronovost PJ, Schneider EB. Limitations of administrative databases. JAMA. 2012;307(24):2589-2590.

25. Italian Ministry of Health. [Italian version of ICD-9-CM: "International Classification of Diseases - 9th revision - Clinical Modification"; 2007]. Available from: http://www.salute.gov.it/imgs/C_17_pubblicazioni_2251_allegato.pdf. Accessed February 16, 2016. 


\section{Publish your work in this journal}

ClinicoEconomics and Outcomes Research is an international, peerreviewed open-access journal focusing on health technology assessment, pharmacoeconomics and outcomes research in the areas of diagnosis, medical devices, and clinical, surgical and pharmacological intervention. The economic impact of health policy and health systems organization also constitute important areas of coverage. The manuscript management system is completely online and includes a very quick and fair peer-review system, which is all easy to use. Visit http://www.dovepress.com/testimonials.php to read real quotes from published authors.

Submit your manuscript here: https://www.dovepress.com/clinicoeconomics-and-outcomes-research-journal 